\title{
In-equalities, Regulation, Ethics \& Records - reflections from a case in Online Trade
}

\author{
Tove Engvall \\ Mid Sweden University \\ 85170 Sundsvall, Sweden
}

\begin{abstract}
In an ethnographic study in online trade at the financial market, different forms of inequalities in client-broker/business relations have been found. It takes expression in for example design of technology, control of and access to information, competence and misuse of trust. Trust is at the center of concern, since that is crucial both to success and a risk for being taken advantage of. This relates to power between actors, responsibilities and accountability. This is where records role as evidence of human acts and conducts have a central role, both in relation to regulation and business ethics. As established structures for ensuring rights and obligations throughout societies are challenged by digitalization and globalization, this has to be recreated in the online context. The article conclude that both regulation and ethics are crucial in forming common values, behaviours and understanding of trust. If not, trust is easily violated which set people in trouble. In order to ensure trust, accountability is an important factor to consider, as well as informal means for ensuring fair behaviours that promotes the building and maintenance of trust among actors. As the technological development challenge processes and means for trust and accountability, new tools ought to be developed. As well as people-related aspects at both personal, business and societal level have to be considered.
\end{abstract}

Keywords: online trade, inequality, records, evidence, ethics

\section{INTRODUCTION}

Digitalization challenges established structures for how we manage justice, rights and obligations throughout societies. Laws often intends to ensure for citizens to be treated as equals, and if someone is violated - according to agreed laws - there will be consequences. This in order to promote fair behaviour.

Archives and records can be used as evidence of actions, activities and transactions (ISO 2016). They can, if related to regulatory frameworks, be acted upon in order to claim rights and obligations. In legal processes, they can be used as proof of whether someone has broken the law. In accountability processes actors can be held accountable for their acts. Common rules and values of what is acceptable and not are ways to create a common ground where participants have a shared notion of what they can expect from each other and trust.

Laws and regulations are not quite keeping up with technology. They are jurisdictional and defined by borders at different levels, such as nation states, municipalities, and regions. Meanwhile internet is a global system in which activities are carried out across jurisdictional borders. "On the one hand this spurs the growth of our economy, while on the other it allows computer crime to know no boundaries. Both lawful and unlawful activity on the Internet pose challenges to jurisdictional authority." (Duranti \& Rogers, 2014, pp. 210-211). There is a growing conflict between national jurisdictions and the global internet, and the growth of multi-national telecommunication and other players create and further an imbalance of rights 
and obligations between industry and consumers (Duranti \& Rogers, 2014). The online context also makes it challenging to control compliance of laws and regulations.

Further more, different values and cultural patterns are crossed in the same online space. In the online environment, common grounds for common value systems have not yet kept pace with the technological development. Yet, businesses are transacted over digital networks between people that will probably never meet, which makes trust a crucial question (Duranti \& Rogers, 2012). Along with this, personal data is a commodity and "this information is being collected, mined, analyzed and used for economic gain, surveillance and research beyond our wildest imaginings" (Duranti \& Rogers, 2014, p. 209). This commodification and sale of information erode trust and personal liberty.

Common rules, rights and obligations and means to enforce them in order to promote fairness, are central in modern societies. They are also key factors in developing trust within societies. Which is something nation states have had a central role in ensuring. With digitalization this becomes more and more difficult to manage within the frames of individual countries, and common ground for trust on a global scale has not yet had time to develop.

This raises questions of how relations online develops in terms of equality and inequality, what role records and data have in shaping these patterns, and what can be considered to promote fair and equal relations.

An example from an ethnographic study in online trade will highlight some challenges and expressions of inequality in this online, international context. Many clients have lost a lot of money due to different reasons. Scam companies, cybercrimes, unequal ICT structures and gaps in legislation and consumer rights are some of the problems that have been indicated, as well as lack of competence and knowledge among trading clients (Engvall, 2017).

Online trade means that a client can trade different assets, such as stocks, forex, commodities and indexes, by access to a trading platform online. This trading platform is provided by a brokerage firm (Investopedia, 2016). "Clients open an account at a website where deposits and withdrawals are made and records of transactions are available. On the trading platform connected to the website, clients can open and close positions in trade" (Engvall, 2017, p. 34).

What emerged as a primary concern in the study, was about trust. What meaning it has and how it is used and abused. Trust is an ethical issue, and it was found in the study that it is connected to relations of power and inequality.

\section{OBJECTIVES, METHOD AND THEORETICAL PERSPECTIVE}

This paper uses results from an ethnographic study in online trade. The study was performed 2015-2017 and included participation in online trade, unstructured interviews and conversations (approximately 100), and semi-structured interviews (8) with brokers in online trade. The conversations and interviews were done primarily by phone or skype. Results from the study has previously been presented in an article (Engvall, 2017a) and a book (Engvall, $2017 \mathrm{~b}$ ), and is here discussed from an ethical and legal perspective, related to the role of recordkeeping.

Ethnography is often used to understand social actions and interactions, and include observations in natural situations, which is then analyzed. It builds on close contact with the studied group and its participants, and gains knowledge by own experience and interpretation. 
The intention is to understand the participants perspectives. The process is often to first gather a thick material, which is then systematized and analyzed within theoretical frameworks (Alvesson \& Sköldberg, 1994). The overall aim with this research is to get a deeper understanding of a part of the online financial market, in order to identify what improvements can be made towards sustainable markets and information systems.

In the study, a reflective approach was used throughout the process. Experiences and insights led to new questions by reflecting on what had been found. That generated new input which was further reflected on. Continuously the approach has been to ask questions and look at the phenomena from different angles, with an intention to increase awareness about it. It has also included reflection and increasing the awareness of one's own perceptions and construction of the texts (Alvesson \& Sköldberg, 1994). According to Alvesson \& Sköldberg (1994), reflexivity include considerations of social, political, theoretical and linguistic aspects, as well as searching for underlying meanings. The purpose is not to define truths, but to open up for understanding and insights. Reflexive research include two elements; interpretation and reflection. Empirical material are interpreted and then reflected upon. The approach is also to go beyond what is taken for granted and search for deeper meanings (Alvesson \& Sköldberg, 1994). Central in the research is to contribute to social benefit, and to ask questions that seeks to make improvements for the benefit of society as a whole.

The research has had an abductive approach. Abduction means that the research often starts with collection and interpretation of empirical material, which is then analyzed with existing theories in order to develop understanding of different patterns and to find deeper meanings and structures. There is often an alteration between interpretation of empirical material, and use of existing theory in analysis of the findings. Insights lead to new questions, which lead to new analysis (Alvesson \& Sköldberg, 1994). The ethnographic study was performed in different phases. First there was a phase of active participation and conversations with brokers. Then experiences were summarized and challenges were identified to continue research around. Broad question areas were made, which were addressed in further conversations. This was a phase of writing, conversations and interviews. After that, there was a new phase of participation, for example in a course in trading and a new broker to trade with, and taking a more active part in the trading. Along with this, there were also further conversations with brokers. After this, there was again a phase of analysis and writing. Some other studies have also been done, for example with interviews with the public administration about the financial market and Big Data (Engvall, 2017c), which contributed to the body of knowledge that has further developed the understanding. All along the way, experiences, conversations, reflection and literature studies build up the body of knowledge and understanding. This article is part in this process, to use the insights from the study and discuss it from the perspective of records role as evidence of peoples' actions and transactions, related to legal and ethical perspectives and how this relates to trust.

\section{Facts, acts and records}

\section{RECORDS, RESPONSIBILITY AND TRUST}

Every social group ensures an ordered development of the relationships among its members by means of rules. Some of the rules of social life arise from the ad hoc consent of small numbers of people; others are established and enforced by an "institution", that is, by a social body firmly built on common needs, and provided with the means and power to satisfy them. The latter rules are compulsory; their violation incurs a sanction or penalty. A social group founded on an organizational principle which gives its institution(s) the capacity of making compulsory rules is a juridical system. Thus, a juridical system is a 
collectivity organized on the basis of a system of rules. The system of rules is called a legal system. (Duranti, 1989-1990, p. 5)

Within legal systems, both human conducts and natural events takes place and exist as facts. Facts that has not been considered in the juridical system, are qualified as juridically irrelevant. Facts that are taken into consideration by the juridical system in which it takes place, are considered to be juridical facts (Duranti, 1989-1990, p. 5). There can also be historical facts that is not juridically relevant. Human facts that is a result from a determined will is called an action or act. Acts can be manifested orally and written. An archival document "implies the presence either of a fact and a will to manifest it or of a will to give origin to a fact. It also indicates a purpose. In fact, the existence of something written, directly or potentially, determines consequences" (Duranti, 1989, p. 16). Central elements are persons, responsibility and competence. This relates to persons as subjects of rights and duties, responsible for their acts, and competence and authority to accomplish an act (Duranti, 1990).

\section{Records function as evidence of acts and facts}

In the international standard for recordkeeping (ISO 15489:1-2016), a record is defined as "information created, received and maintained as evidence and as an asset by an organization or person, in pursuit of legal obligations or in the transaction of business" (ISO 15489:1-2016, p. 2). In order to use records as evidence, it is important to determine its trustworthiness, which is established by the records' authenticity, reliability, integrity and usability (ISO 15489$1: 2016)$. Reliability is about the record as a statement of fact. Authenticity is about the trustworthiness of the record as a record, that it is what it purports to be, free from tampering or corruption. This relies on different factors in the management of records, procedural control, different measures, metadata and audit trails, as well as knowing the original source, provenance and chain of custody (how records have been managed by different actors over time and space), and this have to be transparent (Duranti \& Rogers, 2014). Records reliability and authenticity are key elements of governance in juridical systems, in order to provide trustworthy evidence (Iacovino, 2005). The Archives role as a trusted and impartial third party, also have an important role in providing trustworthiness in records as evidence. That the recordkeeper do not have any interest in manipulating the records in a certain way, but whose role it is to ensure its authenticity, reliability and integrity.

In its role as evidence, records are crucial in juridical and accountability processes. As evidence of what different actors have done and not done in certain situations. Having records does not mean that justice is provided. There is a difference between having records and doing something with it (Hurley, 2005). You need to know what you want to proof and there has to be processes for acting upon the evidence in order for them to be effective and authoritative. Just having records is not enough, they have to be related to a regulatory framework and means for compliance. But rules without evidence is difficult to enforce. And access to records are not enough, they also have to be in order, secure, and that their trustworthiness are assured.

The digital online environment poses specific challenges to the assurance of trustworthiness of records. Research in archives and information science are performed to address this, for example in the InterPARES Trust project. There is also a collaboration between digital forensics and archives and information science, in processes of analysis of evidentiary material. Digital forensics specialists are concerned with identifying and assessing digital objects that may serve as evidence of illegal activities, and to establish their evidentiary capacity. While an archivist is concerned with identifying digital objects, created as records of 
activities, facts and events, and to assess their authenticity, reliability and accuracy to enable accountability and a trustworthy memory (Duranti \& Rogers, 2013).

\section{Records, governance and accountability}

Records are an important part of organization and regulation of relations throughout societies and have a central role in governance in societies and to bind societies together. They support legal and ethical rights and obligations, provide evidence of activities, and are important tools for organizational and democratic accountability which underpins ethical and legal systems (Iacovino, 2005). Records also have symbolic meaning (Ketelaar, 2005) and carry values and ethics. Records can be used both for oppression, and for fairness and liberation, and are instruments of power and control (Ketelaar, 2005).

Iacovino refer to governance as both '"government' and its laws as in a nation-state or organized community, and 'self-government' as a means of control over personal and group behaviour within a self-governing community" (Iacovino, 2005, p. 255). Governance can be based on formal rules and regulations, but also on ethical habits and reciprocal and moral obligations, internalized by the members of a community. Which form the basis for trusting one another. Ethics concerns what is guiding peoples' behaviour, and relates to values, moral and philosophical issues, and consciousness (Merriam Webster, 2018). ${ }^{1}$ According to Iacovino,

Ethics involves relationships between individuals, individuals within a community life, how they live (...) juridical systems also recognize the need for moral principles to bind communities together. A community of interest, such as a profession that has developed a set of ethical standards, plays an important part in the regulatory controls over consistent professional practice. Professionals have a special responsibility to avoid or prevent harms beyond everyday responsibilities. The special responsibility is based on two grounds: an implicit contract that a professional has with society and a moral obligation to use knowledge wisely (Iacovino, 2005, p. 273-274).

Records are used to support individual rights and obligations, and function as evidence of ethical or unethical - and legal or illegal - behaviours and acts, as well as destruction of records (or avoidance of creating records) can be done to cover up unethical or illegal behaviours and acts. In the online environment, the risk of fraudulent manipulation of information has increased, as well as risks related to privacy (Iacovino, 2005, p. 274). Accountability can be seen as part of governance processes. They can be used to assess compliance. But in its simplest form, it means that an actor (whether a government, organization, enterprise or individual) are accountable for their actions they have either brought about or failed to prevent. Records can be used as proof of what happened, was decided etc, and are often seen as more trustworthy than tales. In the global online context, where relationships between sovereign states are replaced by relationships between individuals, social groups and businesses, it is important to develop an understanding of how communities are bound together and trust and responsibility is managed.

\section{Records and trust}

Records as trustworthy documentation of acts and facts are important tools for creation and protection of trust throughout societies. It is an integral part of making societies to function, and for people to interact, make exchanges and have a division of labor. For example, when you go to a doctor, a patient trust that the doctor will work for her/his best, and not to harm 
her/him. There is a documentation of the treatment of the patient, which enables accountability. This function to protect the trust-relationship between doctor and patient. When a person goes to a bank, he/she trusts that they will not steal the money he/she put into an account, and all transactions are documented as proof. This is part in trusting professionals and what they do in their performance of business and expertise, and records are part in ensuring this trust relation. Without trust, you would have to do and control everything yourself. Trust and violation of trust are important ethical issues which to a high degree relates to how people behave and what expectations there are of how people should behave.

Trust has been defined in many ways. In business, trust involves confidence of one party in another, based on an alignment of value systems with respect to specific benefits in a relationship of equals. In jurisprudence, trust is usually described as a relationship of vulnerability, dependence, and reliance in which we participate voluntarily. In substance, trust means having the confidence to act without the full knowledge needed to act. It consists of substituting the information that one does not have with other information. (Duranti \& Rogers, 2014, p. 205)

In the online environment, new processes for interaction between different parties develops, jurisdictions are crossed, and people with different cultural norms meet. This challenge established norms and procedures for trustworthiness, why we have to reconsider how to create, assess and assure trust. Crucial is how information is managed, what policies and practices regarding handling of digital records that exist. Duranti \& Rogers suggest a development of a conceptual understanding of trust with its characteristics, with domain specific theories, techniques, and parameters for assessment, in order to develop cross-cultural and international trust (Duranti \& Rogers, 2014).

There can be different levels of trust, and it may involve different aspects. One level include a relation of a trustee and trustor, where the trustee is in some kind of vulnerability who is seeking aid, advice or protection from the trustor, based on his/her justifiable trustworthiness. Next level of trust is based on good faith, with a general assumption that the person will deal fairly without breaking their word. A further lower level of trust is that of unconscionability, which is based on terms that is unfair to one party (Duranti \& Rogers, 2014).

Online, the terms for trust is not explicitly identified, framed or assured with means for consequences if violated. This leaves individuals and businesses to create and assess their own terms and means for trust. There is also a growing shift from trust in experts to personal interpretation, and to trust friends and social networks rather than professional experts and figures of authority. The question is though, what means for assessing another party's trustworthiness that exist and how to make actors responsible in case of violation of trust.

In the case of online trade, a client can be seen as a trustee, who is trusting the professional's competence. They might go into a business relation in good faith, assuming that the professional will keep their word. Meanwhile, mechanisms for ensuring trust is insufficient and has been violated in different ways, and also makes client-business relations unequal. Along with this, self-trust gets an increased importance.

\section{POWER DIFFERENCIES AND INEQUALITIES IN ONLINE TRADE}

In an ethnographic study in online trade, different forms of inequalities was found in client business relations. What was found was that trust played an important role in this, both in cases of abuse and misuse of power, as well as positively for empowerment and development 
of good business relations. Regulation is a way to create a fair playground and to balance powers on the market. This is also related to professional values and ethics. In the online environment, a lot of changes at a high speed create gaps that ought to be addressed. Inequalities can be expressed as differentiation in power, and in this case of online trade also the ability and conditions for making profit. It includes both to have capability to accomplish something, as well as it can be seen as a relational aspect. People have both internal and external factors working for or against them. Both as a resource for power to accomplish something, but also as power over someone else (using the concepts expressed by Law, 1991). Challenges in terms of power differences have been grouped related to competence; structural aspects; informational and technological structures; and trust, risk and power.

\section{Competence}

A central factor to whether a person makes profit in online trade is level of competence, skills and knowledge, as well as management of personal traits. This counts for both traders and brokers. According to interviewed brokers, one of the main reasons that clients have lost money are that they lack knowledge and competence, and are driven by fear and greed. Many people trade without knowing what they do, which makes them lose a lot of money. This has led to increased initiatives with education of traders. At the same time, marketing often tell people that anyone can be a professional trader after just one course with them, which is a bit misleading. Competence also include an understanding of the online trading environment, and its cultural and specific challenges a trader face, with an awareness of what risks there are. Competence is also important in order to increase confidence and self-trust, which have been raised by brokers as key factors to be successful. This is crucial in order for clients to not be easily convinced to just do what they are being told, but be capable of making informed decisions, as well as managing personal risks of fear and greed. It is when a person trust someone else more than him/herself that he/she risk being taken advantage of and manipulated. At the same time, in order to do business together, involved parties need a certain level of trust and if we should have a specialization in labour, you must be able to trust actors in a professional role. The open environment also requires of people to have a high level of inner strength, integrity towards external pressures, as well as to take responsibility for ones actions. Access to and understanding of trustworthy information are crucial in order to make informed decisions and have control of trading operations. On the other hand, misinformation, disinformation or incomplete information are dis-empowering of clients' possible performance. Timing of access to information also impacts the result. In terms of equality and inequality, professionals have an advantage because of knowledge and access to different resources. This put them in a major position in relation to a client. First of all, the trustworthiness of the information that is shared is crucial and a problem here can be misinformation, disinformation or untimely or incomplete information. Not giving a client crucial information and neglecting what is happening to the client's account can also be as destructive as giving bad information. Therefore, you could say that inequalities also exist in relation to the commitment and dedication a broker have, and what information this broker have access to.

Online trade are performed in a complex, and multicultural, global context, and learning to navigate this are part of the competence that is required to succeed. Different expectations of trust and business ethics may cause problems and is a risk for people to be taken advantage of. As there has not been sufficient societal structures and processes in place to deal with abuse of trust, responsibility lies to a high degree on individuals. As it is today, this make it a question of personal competence to assess probable trustworthiness of different actors. Common norms around trust should be developed, which can be done through regulation and stronger business ethics frameworks. For both of these, records would play an important role as evidence and in governance and compliance. 


\section{Structural aspects}

Complex corporate structures can create confusion, and according to some of the interviewed brokers, they are set up and constructed in a way to avoid accountability and responsibility. Different functions can be performed by different companies, or by different offices in different countries. Combined with communication structures, it can be difficult for a client to address issues with an appropriate person in a company, and to claim their right. In case of scam companies or those who take advantage of their clients, many times the broker never respond, and they never have to meet the client in question. In this way, the technology enable control of communication and is a means for power differentiation (Engvall, 2017, p. 29). Control of communication lies with the companies, which also makes them controlling the 'space' where broker and client meet. It is also a very changing environment, and brokers often change job. Meanwhile, many brokers speak about that they want a long term relation with the client. But the context do not support that. This is one contradiction of how trust is spoken about. Many times people speak about trust, while acting in opposite direction. It is an environment where it is very easy to get away. Fraud companies can just shut down their website and reappear under a different name (Engvall, 2017).

Castells (2000) mean that internet and communication technologies are shaping relations of power by flows of information, wealth and information, and inequalities are created related to this. Beck (2000) has argued that virtual economies make it easier for capital to escape democratic control. In the case of online trade, a problem that has been raised by brokers, are that there are virtual bubbles in which companies place some client's money instead of letting it out on the market. So in case when the client lose money, it goes to the company. This is of course not something that the client get to know. But they can be placed in what is called 'Abook' or 'B-book'. The ease to hide capital like this has been raised by brokers as a main problem, which raises questions of compliance with regulation and business models.

From a consumer rights perspective, the responsibility is to a high degree on the client. Existing processes seem to be related to national contexts as well as the physical environment. It is difficult for consumer rights organizations to act with companies that do not have a physical office. During the case study, a report of a company was made to the police. The police meant that it was difficult for them to act in another country. It is also connected to citizenship. For example, a majority of companies say that they are situated in London. Meanwhile, when the police in London was contacted, they meant that they only proceed with a case for citizens of United Kingdom. In case the company is regulated by for example CySec, they have processes for complaints and there is an ombudsman where clients to a company licensed by CySec can raise their cause. In cases where the company do not have a license, it seems almost impossible to do anything (Engvall, 2017). The research has showed that regulation is crucial in order to have consumer protection frameworks, individual traders do not have any chance with the means that companies have available. The conditions are too inequal from the start.

What can be noticed though, is that people with different nationalities work in this business, for example from eastern Europe, Russia and Balkan countries. The online environment opens up previous barriers related to nationalities, and create new possibilities for people from different countries.

\section{Informational and technological structures}

The collaboration between broker and client is very central in online trading, and the communication between them are important. This is often performed by skype, phone and sometimes e-mail. In regulated companies, telephone calls are recorded. Skype or means to 
share screen is common when brokers want to show and explain things to a client. It is a way to create a shared space, and for them to see the same thing at the same time. It is often argued by brokers that it is a way for clients 'to see with their own eyes in real time what is going on so that they can assess whether it is trustworthy'. This does not say anything about the trustworthiness of the information the brokers are sharing though, they see what the broker is showing them. But it is a way of creating closeness in the relation.

In the relation between business representatives and clients, there is an inequality of information about each other. Companies collect, buy and analyze information about clients and potential clients, which is used in conversations and strategies to make people invest money. People are leaving traces of information in the online environment that is collected and analyzed, and the question is what information clients and public authorities (to ensure consumer protection) have access to about companies?

As Duranti and Rogers (2014) have expressed, the possibilities for using information for different purposes has not only opened up possibilities but also risks regarding individuals privacy, and surveillance. Information are often extracted and accumulated from sources unknown to people. Yet still, people entrust different actors with their data and share information online, where actions on internet leave traces where data about people's habits are collected, analyzed, and commodified, which erodes trust. Traditional policies, practices and infrastructures to ensure trust in records are not enough. Transparency and accountability are key factors of those managing information. Transparency of how information is being collected, managed, used and protected, and assurance of that an actor "can be asked to respond for its actions legally, administratively, and, historically (...). Together, transparency and accountability provide us with knowledge and recourse in the case of failure, thereby promoting trust." (Duranti \& Rogers, 2014, p. 209-210).

Control of communication is not only about control of technology and communication means, but also who is leading the conversation between client and broker. Because brokers often have an information advantage, that is also an advantage in the conversation. According to interviewed brokers, a problem have been brokers who pushes and manipulate clients to invest big amounts of money, and to boost their fear and greed. Supervision has increased though, with controls of brokers' behaviours towards clients.

What was found was that design and functioning of IT systems are relevant to a trader's performance, because it impacts how the user interpret and calculate risks for example. Inaccuracy of information and that certain functions don't work at critical times also impact the results to a high degree. During the case study there were occasions where the system didn't work or the information was inaccurate, which had an impact on the trading. What should be considered is to develop more tools for traders in order to have better control of their trading.

Technological tools, such as leverage (leverage is when invested money is multiplied with a certain number in order to increase the volume of money in trading), increase the difference between profit and loss. Which increase the difference between those who make profit and those who do not succeed. It could be interesting to study how money flows, to see whether there are patterns of centers and peripheries, as well as patterns in winnings and losses.

Related to power and inequalities, access to right information at the right time, control of information, control of clients personal data, control of money as well as control of functions in the system are some aspects identified. This all comes down to records. Trustworthiness of 
data and records, along with transparency and accountability are key factors for fair relationships. In the online internet environment, where relationships are based on the exchange of information, it is a fundamental relation of power to have control over the information; to have access to it, to know whether it is trustworthy and to control who else has access to it and at what point in time. Therefore, equality in an online environment is highly related to management of information and centers around trust; whether someone trust the information or not. Which can be used, misused and exploited.

\section{Trust, risk and power}

Something that emerged during conversations with brokers in the study, was how trust was at the center of concern. A client need to have a certain level of trust in order to invest money with someone. This is also why brokers develop different strategies to make potential clients to trust them. Meanwhile, in order for trustworthiness to exist, it has to be created at different levels; among people, in companies, processes, the technical environment, the information, and societal systems. As it is now, there is a high responsibility on brokers and individuals to create trust and to take care of oneself. Trust lies primarily in personal relations, rather than institutional systems. Inequality depends on what people a client get in contact with, what personal network they have, and how well they manage. It is very difficult to assess who and what is trustworthy or not and better tools for users are required. Trust is also a central element in the process of fraud. A client have to trust the broker in order to be cheated. That is why a trust relationship is basically unequal, since trusting someone else is a way to give that person power.

Trust is a mechanism to manage risks and rests on faith in principles and good intentions and reliability of others. It enables collaboration and sharing of duties. It implies to be willing to take a risk, related to a notion of trustworthiness, which is often based on competence and expertise, honesty, reliability, benevolence, predictability, shared values and care (Öhman \& Lundberg, 2015).

According to Giddens (1990), trust relates to a lack of information because

There would be no need to trust anyone whose activities were continually visible and whose thought processes were transparent, or to trust any system whose workings were wholly known and understood (...) the prime condition of requirements for trust is not lack of power but lack of full information" (Giddens, 1990, p. 33).

Records are used as objects that can be trusted as evidence of activities and transactions. The trust lies in records and records processes, related to regulatory frameworks that provide for rights and obligations and justice are ensured. Records can both replace personal trust, but also support it. Money are as well objects that are trusted, and used in exchanges. If for example person A give something to person B, person A get money in exchange instead of trusting that person B will give something in return, as well as person B might not have what person A want. With digitalization, several functions are performed by technologies and trust is placed in technology and algorithms instead of people and processes. This also have to include functions for justice and consumer rights, or otherwise all control will be on the business side.

Online trade is a high-risk environment, as well as a cero-sum game. When someone make profit, someone else lose money. Due to the high risks, trust is a factor for succeeding. Trust make information to flow more easy, since people are more willing to share information with 
each other. But trust is also a risk in itself, since it makes actors vulnerable to each other. Business models based on mutual benefit are often raised by brokers as a reason to trust them. Since that would make brokers and clients to work towards the same goal and not against each other. In the interviews, care was also raised as a crucial element for success; that a broker care about the client's account and result. Personal responsibility in the professional role was yet another aspect that contribute to the development of trust.

Discussions about economic growth have focused much on external factors, but we now have to put more attention to psychological and relational factors, at all levels (individuals, business and institutional domains). Such as conscious decision-making, management of personal risks, change of destructive patterns, continuous personal leadership, improvements and awareness. Sustainable growth requires an inner growth. Self-trust is not just important for clients, but also for business representatives. Brokers and companies who trust themselves would not need to cheat clients in order to make money. In order for the financial market to be sustainable from an environmental perspective, there have to be a greater level of care in how money is produced and used. The level of energy used by certain activities (such as bitcoin mining) and what people do with their profit is a big impact to consider. Because of the high level of competition, it is very difficult for individual brokers and companies to make ethical choices, it has to also be supported by regulation and be more economically profitable compared to less sustainable choices.

\section{DISCUSSION}

The case study in online trade indicate that inequalities in client - business relations exist at different levels; in communication, information and technological structures, business organizational context, people-related issues, as well as gaps between the online business environment and jurisdictions. In this context individual traders are in a very week position compared to brokers and companies. Trust has been identified as a central element, both as an enabler and a risk. It is crucial for business relations, both initially and also in the long term perspective for growth. But it is also a risk that people will be taken advantage of, since trusting someone put the person in a vulnerable position. This also relates to justice and accountability. In online activities, people with different values meet and interact, and common sets for practice has to be developed in order for it to work.

Laws and ethics are two means to create commonly accepted behaviours, and to have means for compliance and correction. There are often discussions of whether regulation or selfregulation should be applied, but they should not be seen as opposed but rather mutual in good governance. You could say that laws and regulations are explicit and external means for steering behaviours throughout societies, and ethics and norms are implicit and internal means for this. In both cases, records have an important role.

What this research shows, is that absolutely crucial from a client perspective is to have regulation. This ensure consumer rights, but also serve to shape business ethics and common values in the domain. As there for example have been stronger rules about speaking about risks with clients, this has been improved. Because of the high level of competition, and because it is very easy to escape responsibility in the online environment, trusting market actors' free will is not enough. A role of public institutions, is to work for justice among its citizens and to balance power inequalities throughout society. The financial market is a domain that is highly unequal and needs to be balanced if it should provide possibilities for more than the most capital strong actors. For this, better technological means for regulatory institutions are required in order to meet the digital development and to be able to work more proactively. 
Meanwhile, regulation will not be able to cover everything in the complex online environment. Professional values and culture are therefore crucial, to also support business ethics online. With the development of the open environment online, where people have possibilities for direct participation, it will also be crucial with consumer awareness, competence and responsibility. It requires a more proactive sense of responsibility, care and awareness of what effect one's choices and actions have, in relation to the role a person have. This applies on not just individual level, but also business and societal level. Ethical decision-making requires that people act as moral agents, make active choices and analyze their decisions (Iacovino, 2006).

Finding ways for regulatory accountability, professional ethical standards, as well as individual responsibility to work in the same direction can be a way to promote a more sustainable pathway forward. As Iacovino (2006) express, laws and ethics can support each other. Often illegal activities such as fraud, corruption or abuse of people, are also professionally unethical. Legal sanctions and ethical standards are means to set a direction and framework for a common playground. So participants know what they can expect from others and thereby invest their trust in. Online activities cross national borders and jurisdictions, and international cooperation is needed. International frameworks and solutions that can establish and support trust online, will also require provision of authentic, reliable and accurate records (Duranti \& Rogers, 2014). As well as supporting a democratic discourse globally.

Records, which can be used as evidence of actions and transactions, related to accountability processes and regulatory frameworks have over the course of many years functioned to protect and ensure trust, as well as functioning as trusted objects as such. With the development of the online environment, this has to be ensured as well and is crucial to consider in further technological development.

Related to ethics, there are different levels to consider from a records perspective, with different actors involved. At a client perspective it concerns personal ethical behaviour, which could include to be aware of their responsibility in making more conscious and informed decisions and improve risk management, which will require a personal recordkeeping. At business level it include professional ethics and behaviours, which to a high degree involves questions of information and communication management. At societal level it concerns public values and institutional ethics in relation to its citizens, as well as policymaking, regulation and supervision - which requires recordkeeping. It also involve social norms and a collective sense of ethical ideals.

There is never only one solution to a challenge, and both regulation and ethics can be used to support a pathway for good governance and justice, and to develop a trustworthy online environment.

\section{References}

Alvesson, M. \& Sköldberg, K. (1994). Tolkning och reflektion. Vetenskapsfilosofi och kvalitativ metod. [Interpretation and reflection. Philosophy of science and qualitative method]. Studentlitteratur AB, Lund, Sweden.

Beck, U. (2000). What is globalization? Polity Press in association with Blackwell Publishers Ltd.

Castells, M. (2000). The rise of the network society. Second Edition. Blackwell Publishers Ltd. UK

Duranti, L. (1989). Diplomatics: New Uses for an Old Science. Archivaria 28, 1989, pp.

Duranti, L. (1989-1990). Diplomatics: New Uses for an Old Science (Part II). Archivaria 29, (Winter 1989-1990), pp.

Duranti, L. (1990). Diplomatics: New Uses for an Old Science (Part III). Archivaria 30, (Summer 1990), pp. 
Duranti, L. \& Rogers, C. (2012). Trust in digital records: An increasingly cloudy area. Computer Law \& Security Review 28 (2012). Pp. 522-531

Duranti, L. \& Rogers, C. (2014). "Trust in online records and data," in Lowry, J. \& Wamukoya, J. (eds.), Integrity in Government through Records Management: Essays in Honour of Anne Thurston (Farnham: Ashgate, 2014): 203216.

Duranti, L. \& Rogers, C. (2013). Memory Forensics: Integrating Digital Forensics with Archival Science for Trusting Records and Data. eForensics magazine (online Polish Journal for Digital Forensics) (October 2013): http://eforensicsmag.com/memory-forensics-step-by-step-free/

Engvall, T. (2016). Fear, Greed and Lack of Trust In Online Financial Trade. Journal of Administrative Sciences and Technology. Vol. 2017 (2017), Article ID 106163, 10 pages

Engvall, T. (2017a). Fear, greed and lack of trust in online financial trade. Journal of Administrative Sciences and Technology. Vol. 2017 (2017), Article ID 106163, 10 pages. DOI: 10.5171/2017.106163

Engvall, T. (2017b). Trade, Trust and Information Power - In Transition to Sustainability. Lambert Academic Publishing, Mauritius

Engvall, T. (2017c). The data dilemma: who is in control? Eabh international workshop: The Data Dilemma: A Risk or a Crisis? 2017-10-11, Zagreb

Giddens, A. (1990). The consequences of modernity. Stanford University Press

Giddens, A. (2002). Runaway world. How globalization is reshaping our lives. Profile Books Ltd, UK

Hurley, C. (2005). Recordkeeping and accountability. In McKemmish, S., Piggott, M., Reed, B. \& Upward, F. (Eds). Archives: Recordkeeping in Society. Wagga Wagga, New South Wales, pp. 223-253

Iacovino, L. (2005). Recordkeeping and juridical governance. In McKemmish, S. Piggott, M., Reed, B. \& Upward, F. (Eds). Archives: Recordkeeping in Society. Wagga Wagga, New South Wales

Iacovino, L. (2006). Recordkeeping, ethics and law: regulatory models, participant relationships and risghts and responsibilities in the Online World. Springer

International Organization for Standardization (2016). Information and documentation - Records management Part 1: Concepts and principles (ISO 15489-1:2016, IDT). Swedish Standards Institute, Stockholm

Ketelaar, E. (2005). Recordkeeping and societal power. In McKemmish, S., Piggott, M., Reed, B. \& Upward, F. (Eds). Archives: Recordkeeping in Society. Wagga Wagga, New South Wales

Merriam-Webster (2018). https://www.merriam-webster.com/dictionary/ethics accessed 2018-05-30

Öhman, P. \& Lundberg, H. (Eds.). (2015). Trovärdighet och förtroende i ekonomiska relationer. (Credibility and confidence in economic relations.) Studentlitteratur AB, Lund 